Jurnal Interpretasi Hukum | ISSN: 2746-5047

Vol. 2, No. 3-Desember 2021, Hal. 607-610| Tersedia online di

https://www.ejournal.warmadewa.ac.id/index.php/juinhum

DOI: https://doi.org/10.22225/juinhum.2.3.4145.607-611

\title{
EFEKTIFITAS PERDA KABUPATEN KLUNGKUNG NO 2 TAHUN 2010 DALAM UPAYA PELESTARIAN LINGKUNGAN DI PANTAI WATU KLOTOK
}

\author{
Ketut Danu Yudistira, Anak Agung Sagung Laksmi Dewi, Luh Putu Suryani \\ Fakultas Hukum, Universitas Warmadewa, Denpasar-Bali, Indonesia \\ Danuyudistira1107@gmail.com, laksmiidewi29@gmail.com,dputusuryani099@gmail.com
}

\begin{abstract}
Abstrak
Keadaan lingkungan di Kabupaten Klungkung telah menunjukkan beberapa tanda peningkatan kerusakan dan pencemaran lingkungan setiap tahunnya. Untuk menjaga dan melestarikan lingkungan hidup oleh masyarakat sekitar, maka Pemerintah Kabupaten Klungkung mengeluarkan Perda Nomor 2 Tahun 2010 tentang Pengendalian Kerusakan dan Pencemaran Lingkungan Hidup. Tujuan penelitian ini untuk mengkaji bagaimana efektifitas Perda Nomor 2 Tahun 2010 dan menelaah kendala-kendala dalam penegakan Perda Nomor 2 Tahun 2010. Penelitian ini didesain dengan penelitian hukum empiris dengan pendekatan perundang-undangan dan konseptual. Data dikumpulkan melalui teknik wawancara lapangan. Data yang digunakan yaitu data primer dan sekunder. Setelah data penelitian terkumpul, selanjutnya peneliti menganalisis menggunakan metode kualitatif deskriptiif. Hasil penelitian menunjukkan bahwa efektifitas Perda dalam upaya menghentikan tingkat pencemaran di pantai Watu Klotok dengan upaya preventif dan upaya represif melalui. Sanksi administratif berupa teguran lisan, teguran tertulis, sanksi pidana denda atau perdata atas kerusakan atau pencemaran lingkungan. Adapun kendala dalam penerapan perda ini yaitu aparat penegak hukum, kebudayaan masyarakat, ekonomi serta kesadaran masyarakat. Sehingga efektifitas Perda tersebut belum diterapkan secara efektif oleh para penegak hukum dalam hal pemberian sanksi. Oleh karena itu Pemerintah Kabupaten Klungkung harus lebih tegas dan bijaksana dalam menerapkan Peraturan Hukum yang ada.
\end{abstract}

Kata Kunci: Efektifitas, Kerusakan, Pencemaran Lingkungan, Perda

\begin{abstract}
The environmental condition in Klungkung Regency has shown some signs of increasing environmental damage and pollution every year. To maintain and preserve the environment by the surrounding community, the Klungkung Regency Government issued Regional Regulation Number 2 of 2010 concerning Control of Environmental Damage and Pollution. The purposes of this study are to examine the effectiveness of Perda No. 2 of 2010 and to examine the obstacles in enforcing Perda No. 2 of 2010. This study was designed with empirical legal research with a statutory and conceptual approach. Data were collected through field interview techniques. The data used are primary and secondary data. After the research data was collected, the researchers then analyzed using descriptive qualitative methods. The results showed that the effectiveness of the Regional Regulation in an effort to stop the level of pollution on the Watu Klotok beach with preventive and repressive efforts through. Administrative sanctions in the form of verbal warnings, written warnings, criminal sanctions or civil fines for environmental damage or pollution. The obstacles in implementing this regional regulation are law enforcement officers, community culture, economy and public awareness. So that the effectiveness of the regulation has not been implemented effectively by law enforcers in terms of imposing sanctions. Therefore, the Klungkung Regency Government must be more firm and wise in implementing the existing legal regulations.
\end{abstract}

Keywords: Effectiveness, Damage and Pollution, Perda

\section{PENDAHULUAN}

Lingkungan memegang peranan sangat penting dalam kehidupan manusia karena antara keduanya ada hubungan timbal balik yang saling mempengaruhi antara satu dengan yang lainnya (Ansari, 2014). Manusia hidup dengan tingkah lakunya dapat mempengaruhi lingkungan baik itu mencemari, merusak atau melestarikan lingkungan itu sendiri sedangkan makhluk hidup lainnya tidak demikian (Sodikin, 2007). Isu penting dalam setiap proses pembangunan baik ditingkat Nasional maupun Internasional adalah kerusakan dan pencemaran lingkungan (Santoso, 2016). Saat ini melihat pesatnya perkembangan pembangunan untuk kesejahteraan dan kemajuan masyarakat juga dapat mengancam keberlangsungan alam dan makhluk hidup lainnya. 
Ada beberapa penelitian terdahulu yang mengkaji masalah yang relevan dengan penelitian saat ini yaitu (Suharjo, 2002) \& (Risjani, 2018) mengungkapkan dalam menjaga kelestarian lingkungan baik perbuatan dari masyarakat lokal sendiri maupun dari luar merupakan tugas pemerintah dalam memberikan solusi, tindakan yang merusak lingkungan meliputi membuang sampah sembarangan, menebang pohon dan merusak pemandangan alam yang ada disekitar. Untuk mengatasi hal ini masing-masing otonomi daerah membuat peraturan daerah yang mengatur lingkungan hidup. Penelitian lain Taufiq, (2014) Nilai-nilai kearifan lokal sebagai upaya pemeliharaan lingkungan tercermin dari aktifitas warga dalam memelihara sumber mata air, memelihara kelestarian hutan rakyat, memelihara kebersihan lingkungan dan semangat gotong royong masyarakat dalam menjaga lingkungan tetap bersih.

Sekalipun sudah banyak penelitian terdahulu yang mengkaji permasalahn ini bahkan Pemerintah Kabupaten Klungkung mengeluarkan Peraturan Daerah Nomor 2 Tahun 2010 tentang Pengendalian Kerusakan dan Pencemaran Lingkungan Hidup dalam rangka pengelolaan sumber daya alam dan perlindungan lingkungan hidup yang diharapkan dapat menjadi landasan hukum dari permasalahan kerusakan dan pencemaran lingkungan khususnya dalam menangani permasalahan di pantai Watu Klotok yang sampai saat ini belum menemukan jalan keluar untuk penyelesaiannya. Kenyataan ini yang membuat peneliti ingin meneruskan penelitian ini dengan tujuan untuk mengkaji bagaimana efektifitas Perda Nomor 2 Tahun 2010 dan menelaah kendala-kendala dalam penegakan Perda Nomor 2 Tahun 2010

\section{METODE PENELITIAN}

Metode penelitian yang digunakan dalam penelitian ini adalah metode penelitian hukum empiris. Penelitian hukum empiris artinya seluruh daya upaya dalam mencari dan menemukan jawaban yang benar dan atau jawaban yang tidak sesekali keliru terhadap suatu masalah, guna menjawab segala macam permasalahan hukum untuk itu diperlukan hasil penelitian yang cermat dan sahih untuk menerangkan, menjelaskan dan menjawab permasalahan yang ada (Muhammad, 2008). Penelitian hukum ini menggunakan penelitian hukum empiris. Dalam penelitian ini hukum dikonsepkan sebagai suatu gejala empiris yang dapat diamati dalam kehidupan nyata pada masyarakat sehingga data yang digunakan dalam penelitian ini adalah data primer dan data sekunder yang diperoleh melalui wawancara lapangan. Keseluruhan dari data yang dikumpulkan baik data primer maupun data sekunder tersebut akan diolah dan dianalisis dengan deskriptif kualitatif (Emzir, 2012).

\section{HASIL DAN PEMBAHASAN}

\section{Efektifitas Peraturan Daerah No. 2 Tahun 2010 dalam Upaya Pelestarian Lingkungan di Pantai watu Klotok}

Dengan berlakunya Undang-undang No. 23 Tahun 2014 tentang Pemerintahan Daerah, dijelaskan bahwa sebagian besar kewenangan pengelolaan lingkungan dan pelaksanaan pembangunan berkelanjutan menjadi kewenangan Pemerintahan Daerah. Dilimpahkannya kewenangan pengelolaan lingkungan hidup dari Pemerintah Pusat ke Pemerintahan Daerah, maka muncul semacam kecemasan bahwa penurunan terhadap mutu lingkungan hidup akan terjadi. Ini disebabkan oleh dua hal. Pertama, karena adanya kekhawatiran bahwa Pemerintahan Daerah cenderung lebih mengutamakan Pendapatan Asli Daerah. Oleh karenanya upaya penyelamatan lingkungan menjadi terabaikan. Kedua, Pemerintahan Daerah belum siap dengan SDM yang memiliki kemampuan dan pengetahuan untuk dalam pengelolaan lingkungan yang mampu menciptakan pembangunan lingkungan yang berkelanjutan. Kecemasan akan hal di atas dapat ditangkal bila Pemerintahan Daerah berupaya untuk melakukan peningkatan kapasitas dan kemampuan SDM dalam melakukan pengelolaan dan peningkatan mutu lingkungan hidup yang inovatif, efektif, kreatif dan efisien serta menciptakan pemerintahan yang baik (good governance) melalui pelaksanaan kewenangan, politik, ekonomi, dan administrasi dalam mengelola permasalah bangsa secara efektif dan efisien serta responsif terhadap kebutuhan masyarakat itu sendiri (Husin, 2009).

Seperti diketahui Kabupaten Klungkung kaya akan pantai berpasir hitam dengan hasil batu sikat yang melimpah salah satunya terdapat di pantai Watu Klotok. Walaupun sering ada yang menyebutnya dengan pantai Batu Klotok, karena arti dari watu dalam bahasa Bali adalah Batu. Sedangkan Klotok memiliki artian "berbunyi", jadi asal mula penamaannya yaitu ditemukannya sebuah batu yang berbunyi. Di lokasi pantai Watu Klotok juga terdapat sebuah pura kahyangan jagat 
bernama Pura Watu Klotok dimana masyarakat hindu bali banyak melakukan kegiatan keagamaan. Pantai Watu Klotok berlokasi di wilayah Banjar Celepik, Desa Tojan, Kabupaten Klungkung berjarak sekitar $7 \mathrm{~km}$ dari Pusat Kota Semarapura. Sangat disayangkan kehidupan masyarakat pesisir pantai identik dengan kemiskinan. Lautan luas tidak dapat memberi penghidupan yang layak karena berbagai keterbatasan. Untuk bisa bertahan hidup, merekapun mencari batu sikat seperti yang banyak ditemui di pantai Watu Klotok. Melalui pengamatan di pantai Watu Klotok, bahwa di daerah pesisir pantai ini telah terjadi banyak kerusakan-kerusakan lingkungan akibat aktivitas-aktivitas penduduk setempat dan kerusakan ini semakin besar tekanannya akibat kurangnya atau bahkan tidak adanya pengetahuan masyarakat setempat dalam pengelolaan, pelestarian serta pengawasan terhadap terjaganya kelestarian dan keseimbangan ekosistem dan sumber daya alam hayati di daerah tersebut. Hal ini tampak dari berbagai kerusakan-kerusakan lingkungan yang ada dan sangat jelas terlihat dari beberapa fakta yang ditemui dilapangan antara lain adanya proses erosi atau abrasi yaitu proses tergerusnya atau terkikisnya garis pantai, banyaknya bangunan liar semi permanen pedagang dan pengepul batu sikat serta rendahnya kepedulian masyarakat terhadap kebersihan dan kelestarian pantai.

Dari hasil wawancara di Kantor Dinas Lingkungan Hidup dengan Kepala Seksi Pengendalian Pencemaran dan Kerusakan I Wayan Adnyana, sebagai pihak pemerintah Kabupaten Klungkung sendiri sudah melakukan berbagai upaya untuk menghentikan tingkat pencemaran di pantai Watu Klotok salah satunya dengan upaya preventif yaitu dengan mengadakan upaya pembinaan, penyuluhan dan penerangan melalui sosialisasi kepada masyarakat pesisir pantai Watu Klotok. Serta upaya represif dalam melakukan penanggulangan pencemaran dan kerusakan lingkungan dengan pemberian sanksi administratif baik berupa teguran lisan maupun tertulis serta sanksi pidana denda atau perdata berupa ganti rugi atas kerusakan atau pencemaran lingkungan yang terjadi.

Dalam hal penegakan mengenai implementasi Peraturan Daerah Kabupaten Klungkung Nomor 2 Tahun 2010 dari hasil wawancara bersama Kepala Bidang Penegakan Peraturan Perundangundangan Satuan Polisi Pamong Praja dan Damkar, I Nengah Tambun, SH menyatakan bahwa pihaknya telah melakukan pendekatan dengan melakukan sosialisasi kepada masyarakat pesisir yang mencari batu sikat dengan melibatkan aparat desa maupun pecalang untuk tidak lagi mengambil batu sikat di pantai Watu Klotok dan memberikan pemahaman akan dampak lingkungan yang akan ditimbulkan. Selain memantau dan membina aparat terkait, di Pemerintah Kabupaten Klungkung telah memasang papan larangan yang menerangkan pelanggaran Peraturan Daerah Nomor 2 Tahun 2010 serta mencantumkan sanksi denda yang tidak sedikit yang mencapai 50 juta atau kurungan penjara selama 6 bulan. Dari upaya-upaya dan sosialisasi tersebut diharapkan masyarakat sadar akan dampak yang ditimbulkan dari pencarian batu sikat serta bahaya abrasi yang mengancam kelangsungan hidup mereka.

\section{Kendala-kendala dalam Penegakan Perda Kabupaten Klungkung No. 2 Tahun 2010 dalam Upaya Pelestarian Lingkungan di Pantai Watu Klotok}

Menurut Wahab, (2002) apapun kebijakan yang dibuat oleh sebuah negara sebenarnya beresiko untuk gagal, adapun kegagalan kebijaksanaan dapat dibagi dalam dua kategori, yaitu non implementation (tidak diimplementasikan) dan unsuccessful implementation (implementasi yang tidak berhasil). Walaupun telah direncanakan dengan terarah, hambatan atau kendala pasti akan ditemui oleh Pemerintah Kabupaten Klungkung. Begitu juga dengan aparat penegak hukum dalam menegakkan Peraturan Daerah yang datangnya bisa dari dalam (intern) maupun dari luar (external). Non implementation dapat dilihat dari tidak terimplementasikannya Peraturan Daerah No. 2 Tahun 2010 dalam hal pemberian sanksi hukum terhadap pelaku perusakan dan pencemaran lingkungan di wilayah Pantai Watu Klotok.

Beberapa faktor yang dapat mempengaruhi penegakan hukum yaitu ada 5 (lima) antara lain adalah faktor hukumnya itu sendiri, para penegak hukum, sarana dan atau prasarana serta faktor masyarakat dan kebudayaan (Soekanto, 2007). Oleh karena itu dari hasil penelitian kendala-kendala yang ditemui Pemerintah Kabupaten Klungkung dalam menangani kerusakan dan pencemaran lingkungan hidup di wilayah Pantai Watu Klotok yaitu faktor implementasi aturan hukum, faktor aparat penegak hukum, faktor kebudayaan masyarakat, faktor ekonomi, dan faktor kesadaran masyarakat. Adapun upaya yang ditempuh untuk mengatasi kendala yang ada adalah dengan upaya preventif yaitu memberikan pembinaan dan penyuluhan akan bahaya dari perusakan dan pencemaran 
lingkungan yang dilakukan. Upaya represif yang ditempuh yaitu dengan memberikan sanksi yang tegas berupa teguran lisan, teguran tertulis, sanksi pidana dan perdata bagi pelaku pencemaran dan perusakan lingkungan di wilayah Pantai Watu Klotok. Upaya-upaya yang ditempuh oleh Pemerintah Kabupaten Klungkung tersebut, belumlah cukup efektif dalam penegakan Perda No. 2 Tahun 2010 dalam menertibkan para pencari batu sikat. Terbukti bahwa masih banyaknya masyarakat yang berbondong- bondong mencari batu sikat setiap harinya di Pantai ini, Pemerintah Kabupaten Klungkung dengan segenap jajarannya masih mencari jalan keluar dan solusi dalam mengatasi permasalahan yang terjadi selama ini di wilayah Pantai Watu Klotok Kabupaten Klungkung.

\section{SIMPULAN DAN SARAN}

1. Simpulan

Berdasarkan hasil analisis data dapat disimpulkan bahwa efektivitas Perda Kabupaten Klungkung Nomor 2 Tahun 2010 tentang Pengendalian Kerusakan dan Pencemaran Lingkungan Hidup belum diterapkan secara efektif oleh para penegak hukumnya. Implementasi yang seharusnya diterapkan terkesan kaku dan tidak ada jalan keluarnya dikarenakan Pemerintah Kabupaten Klungkung sendiri terkesan setengah hati di dalam menerapkan Perda yang sudah di tetapkan, dilihat dari lemahnya sanksi hukum yang diterima oleh para pelaku perusakan lingkungan hidup di wilayah Pantai Watu Klotok. Belum lagi kurangnya kerjasama antara instansi-instansi terkait di dalam menegakkan Perda No. 2 Tahun 2010. Kendala-kendala yang ditemui yaitu faktor hukumnya, faktor penegak hukum, faktor sarana dan prasarana, faktor kebudayaan, dan faktor masyarakat. Adapun upaya yang ditempuh untuk mengatasi kendala yang ada adalah dengan upaya preventif yaitu memberikan pembinaan dan penyuluhan akan bahaya dari perusakan dan pencemaran lingkungan yang dilakukan. Upaya represif yang ditempuh yaitu dengan memberikan sanksi yang tegas berupa teguran lisan, teguran tertulis, sanksi pidana dan perdata bagi pelaku pencemaran dan perusakan lingkungan di wilayah Pantai Watu Klotok.

\section{Saran}

Berkaitan simpulan di atas, maka adapun saran dari peneliti yaitu Pemerintah Kabupaten Klungkung harus lebih tegas dan bijaksana dalam menerapkan Peraturan Hukum yang ada. Implementasikan Perda No. 2 Tahun 2010 dengan jalan pemberian sanksi hukum yang tegas bagi para pelaku perusakan dan pencemaran lingkungan hidup. Kemudian untuk mengatasi kendala-kendala yang ditemui dalam penerapan Perda No. 2 Tahun 2010 di wilayah Pantai Watu Klotok, maka perlu ditingkatkannya penerapan dan pemberian sanksi yang tegas dan nyata bagi para pelaku perusakan dan pencemaran lingkungan agar adanya efek jera yang ditimbulkan bagi yang melanggar. Sehingga aturan hukum yang ada berjalan sesuai dengan fungsinya dan tercipta ketertiban dalam masyarakat.

\section{DAFTAR PUSTAKA}

Ansari, M. (2014). Implikasi Pengaturan Lingkungan Hidup terhadap Peraturan Perundang-Undangan dalam Kegiatan Bisnis (Perspektif Konstitusi). Jurnal Konstitusi, 11(2), 276-295.

Emzir. (2012). Metodologi Penelitian Kualitatif Analisis Data. Rajawali: Jakarta.

Husin, S. (2009). Penegakan Hukum Lingkungan Indonesia. Sinar Grafika: Jakarta.

Muhammad, A. (2008). Hukum Pengangkutan Niaga. PT. Citra Aditya Bakti.

Risjani, O. jufri dan Y. (2018). Indikator Pencemaran Lingkungan. Yogyakarta: Deepublish.

Santoso, M. A. (2016). Pertanggungjawaban Pidana Pencemaran Lingkungan Hidup yang Dilakukan oleh Korporasi. Jurnal Cakrawala Hukum, 7(2), 216-228.

Sodikin. (2007). Penegakan Hukum Lingkungan. Djambatan: Jakarta.

Soekanto, S. (2007). Faktor-Faktor yang Mempengaruhi Penegakan Hukum. PT Raja Grafindo Persada.

Suharjo. (2002). Kondisi Pengelolaan Sampah dan Pengaruh Terhadap Kesehatan Masyarakat di Dki Jakarta. In Media Litbang Kesehatan (Vol. 12, Issue 4, pp. 37-42).

Taufiq, A. (2014). Upaya Pemeliharaan Lingkungan oleh Masyarakat di Kampung Sukadaya Kabupaten Subang. Jurnal Gea, 14(2), 124-134.

Wahab, S. A. (2002). Analisis Kebijakan Publik. Bumi Aksara: Jakarta. 